\title{
Long-term NMDAR antagonism correlates reduced astrocytic glutamate uptake with anxiety-like phenotype
}

\author{
Eduardo R. Zimmer1, Vitor R. Torrez', Eduardo Kalinine1,2, Marina C. Augustin', \\ Kamila C. Zenki ${ }^{1}$, Roberto F. Almeida ${ }^{1}$, Gisele Hansel ${ }^{1}$, Alexandre P. Muller ${ }^{1,3}$, \\ Diogo O. Souza ${ }^{1}$, Rodrigo Machado-Vieira ${ }^{4,5,6}$ and Luis V. Portela ${ }^{1 *}$
}

\begin{abstract}
'Department of Biochemistry, Universidade Federal do Rio Grande do Sul, Porto Alegre, Brazil, ${ }^{2}$ Department of Physiology, Universidade Federal de Sergipe, São Cristovão, Brazil, ${ }^{3}$ Laboratory of Exercise, Biochemistry and Physiology, Universidade do Extremo Sul Catarinense, Criciúma, Brazil, ${ }^{4}$ Laboratory of Neuroscience, LIM-27, Institute and Department of Psychiatry, Universidade de São Paulo, São Paulo, Brazil, ${ }^{5}$ Center for Interdisciplinary Research on Applied Neurosciences (NAPNA), Universidade de São Paulo, São Paulo, Brazil, ${ }^{6}$ Experimental Therapeutics and Pathophysiology Branch, National Institute of Mental Health, National Institutes of Health, Bethesda, MD, USA
\end{abstract}

\section{OPEN ACCESS}

Edited by:

Johann Steiner,

Otto-von-Guericke University

Magdeburg, Germany

Reviewed by:

Francisco Ciruela,

Universitat de Barcelona, Spain

Paul Guest,

University of Cambridge, UK

*Correspondence: Luis V. Portela,

Department of Biochemistry, Universidade Federal do Rio Grande do Sul, 2600 Ramiro Barcelos Street, 90035-003, Porto Alegre, Rio Grande

do Sul, Brazil

roskaportela@gmail.com

Received: 14 April 2015

Accepted: 22 May 2015

Published: 03 June 2015

Citation:

Zimmer ER, Torrez VR, Kalinine E, Augustin MC, Zenki KC, Almeida RF, Hansel G, Muller AP, Souza DO, Machado-Vieira $R$ and Portela $L V$

(2015) Long-term NMDAR

antagonism correlates reduced astrocytic glutamate uptake with anxiety-like phenotype.

Front. Cell. Neurosci. 9:219. doi: 10.3389/fncel.2015.00219
The role of glutamate $\mathrm{N}$-methyl-D-aspartate receptor (NMDAR) hypofunction has been extensively studied in schizophrenia; however, less is known about its role in anxiety disorders. Recently, it was demonstrated that astrocytic GLT-1 blockade leads to an anxiety-like phenotype. Although astrocytes are capable of modulating NMDAR activity through glutamate uptake transporters, the relationship between astrocytic glutamate uptake and the development of an anxiety phenotype remains poorly explored. Here, we aimed to investigative whether long-term antagonism of NMDAR impacts anxiety-related behaviors and astrocytic glutamate uptake. Memantine, an NMDAR antagonist, was administered daily for 24 days to healthy adult CF-1 mice by oral gavage at doses of 5,10 , or $20 \mathrm{mg} / \mathrm{kg}$. The mice were submitted to a sequential battery of behavioral tests (open field, light-dark box and elevated plus-maze tests). We then evaluated glutamate uptake activity and the immunocontents of glutamate transporters in the frontoparietal cortex and hippocampus. Our results demonstrated that long-term administration of memantine induces anxiety-like behavior in mice in the light-dark box and elevated plus-maze paradigms. Additionally, the administration of memantine decreased glutamate uptake activity in both the frontoparietal cortex and hippocampus without altering the immunocontent of either GLT-1 or GLAST. Remarkably, the memantine-induced reduction in glutamate uptake was correlated with enhancement of an anxiety-like phenotype. In conclusion, long-term NMDAR antagonism with memantine induces anxiety-like behavior that is associated with reduced glutamate uptake activity but that is not dependent on GLT-1 or GLAST protein expression. Our study suggests that NMDAR and glutamate uptake hypofunction may contribute to the development of conditions that fall within the category of anxiety disorders.

Keywords: anxiety, astrocytes, behavior, glutamate, memantine 


\section{Introduction}

Anxiety disorders are among the most prevalent psychiatric conditions worldwide. These disorders have been associated with social isolation, alcoholism, and increased suicide attempts and are also considered to be risk factors for the development of additional psychiatric disorders (Gross and Hen, 2004). Hence, it is imperative to understand the neurobiological mechanisms that are associated with anxiety disorders. It has recently been proposed that a functional imbalance of the tripartite glutamatergic synapse plays a role in anxiety disorders (Clement and Chapouthier, 1998; Nutt and Malizia, 2001; Nemeroff, 2003; Machado-Vieira et al., 2009, 2012). Indeed, glutamatergic neurotransmission offers multiple potential pharmacological targets for treating anxiety-related disorders, such as postsynaptic receptor signaling, presynaptic glutamate release, and astrocytic glutamate uptake (Szabo et al., 2009; Zarate et al., 2010; Riaza Bermudo-Soriano et al., 2012; Pilc et al., 2013).

Currently, antagonism of $N$-methyl-D-aspartate receptor (NMDAR) has been proposed as a feasible strategy for reducing the major symptoms that are linked to anxiety-like behavior (Cortese and Phan, 2005). Indeed, when memantine, an NMDAR antagonist, is administered to patients presenting with depression, anxiety or obsessive-compulsive disorder, their neuropsychiatric symptoms appear to be relieved (Tariot et al., 2004; Sani et al., 2012). By contrast, a recent work demonstrated that chronic antagonism of NMDAR induces elevated anxiety in healthy mice (Hanson et al., 2014). Overall, the current data that are available regarding the association between the use of NMDAR antagonists and the presentation of anxiety-related behaviors refute a simple model of dose-effect and instead seem to be closely related to the regimen, type of drug, or route of administration (Silvestre et al., 1997; Riaza Bermudo-Soriano et al., 2012; Schwartz et al., 2012). Additionally, it is prudent to consider that glutamatergic neurotransmission involves not only neuronal receptors (ionotropic and metabotropic) but also astroglial transporters that participate in neuron-astrocyte coupling.

Two major astroglial $\mathrm{Na}^{+}$-dependent glutamate transporters, glutamate transporter 1 (GLT-1, also known as EAAT2) and glutamate aspartate transporter (GLAST, also known as EAAT1), take up glutamate from synapses to maintain the homeostasis that is necessary to orchestrate the physiological activity of receptors (Danbolt, 2001). Remarkably, cerebral GLT-1 and GLAST are predominately localized in astrocytes, with very low expression in other cell types (Zhou and Danbolt, 2014). Moreover, astrocytes account for $95 \%$ of the glutamate uptake activity in the brain (Danbolt et al., 1992; Lehre and Danbolt, 1998). Importantly, a recent work demonstrated that cerebral microinjection of the GLT-1 inhibitor, dihydrokainic acid (DHK), induced anhedonia and anxiety in rats (John et al., 2015). Thus, one could claim that astrocytic dysfunction may have a considerable impact on the expression of anxiety-like phenotypes (Bechtholt-Gompf et al., 2010; Schroeter et al., 2010; Lee et al., 2013). Based on the principles of neuron-astrocyte coupling, we hypothesized that long-term antagonism of NMDAR would impact astrocytic function and that this would likely affect anxiety phenotype.

In this study, we aimed to investigate the impact of long-term NMDAR antagonism by memantine on anxietyrelated paradigms and their potential association with astrocytic glutamate transport.

\section{Materials and Methods}

\section{Animals}

Three-month-old CF-1 mice were housed in standard cages $(48 \mathrm{~cm} \times 26 \mathrm{~cm})$. The animals were kept in a room with controlled temperature $\left(22^{\circ} \mathrm{C}\right)$ under a $12 \mathrm{~h}$ light $/ 12 \mathrm{~h}$ dark cycle (lights on at $7 \mathrm{am}$ ) and had free access to food and water. The mice $(n=40)$ were randomized into four groups: control (CO), memantine $5 \mathrm{mg}$ (MN5), memantine $10 \mathrm{mg}$ (MN10), and memantine $20 \mathrm{mg}$ (MN20). To avoid social isolation, we maintained two animals per cage (Leasure and Decker, 2009). All behavioral tests were performed between 1:00 pm and 5:00 $\mathrm{pm}$. All experiments were conducted in accordance with official governmental guidelines in compliance with the Federation of Brazilian Societies for Experimental Biology and were approved by the Ethical Committee of the Federal University of Rio Grande do Sul, Brazil.

\section{Drug Administration}

Memantine (Sigma, USA) was dissolved in distilled water at three different concentrations $(0.5,1.0$, and $2.0 \mathrm{mg} / \mathrm{mL})$ to standardize the volume used for oral administration and reach the desired dose. For 24 days, the animals received daily administration of either 5,10 , or $20 \mathrm{mg} / \mathrm{kg}$ of memantine, or an equivalent volume of distilled water, via oral gavage. Body weight and food intake were monitored. All groups received oral gavage at $1 \mathrm{~h}$ after each behavioral task.

\section{Open Field Test}

On the 22nd day, the animals were submitted to an open field task to evaluate spontaneous locomotion and exploratory activity. The apparatus was made of a black-painted box measuring $50 \mathrm{~cm} \times 50 \mathrm{~cm}$ and was surrounded by $50 \mathrm{~cm}$ high walls. The experiments were conducted in a quiet room under low-intensity light (12 lx). Each mouse ( $n=10$ per group) was placed in the center of the arena, and the distance traveled (total and central zone), time spent in the central zone, and mean speed were measured over a course of $10 \mathrm{~min}$ (Muller et al., 2012). The experiment was recorded with a video camera that was positioned above the arena. The analysis was performed using a computeroperated tracking system (Any-maze, Stoelting, Woods Dale, IL, USA).

\section{Light-Dark Task}

On the 23rd day, the light-dark task was performed as previously described (Crawley and Goodwin, 1980) with some modifications to analyze anxiety profiles. The light-dark apparatus consisted of a wood rectangular box with two separated chambers. One chamber had black walls and floor $(50 \mathrm{~cm} \times 50 \mathrm{~cm} \times 50 \mathrm{~cm})$ 
and was not illuminated. The other side had white walls and floor $(50 \mathrm{~cm} \times 50 \mathrm{~cm} \times 50 \mathrm{~cm})$ and was illuminated by a $100 \mathrm{~W}$ white lamp that was placed overhead. The two compartments were separated by a wall, which had a small opening at floor level. For each experiment, an animal ( $n=10$ per group) was initially placed in the white chamber and then allowed to explore the two-chamber area for a duration of $5 \mathrm{~min}$. The following parameters were recorded by a trained and blinded-to-treatment observer: number of transitions between the two chambers, time spent in the light chamber, and risk assessment behavior. After each experiment, the apparatus was cleaned with $70 \%$ alcohol and dried before being used with the next animal.

\section{Elevated Plus-Maze Task}

On the 24th day, the animals were submitted to an elevated plus-maze task to evaluate further signs of anxiety-like behavior. The elevated plus-maze was performed as previously described (Pellow, 1986). The elevated plus-maze apparatus consisted of two open arms $(30 \mathrm{~cm} \times 5 \mathrm{~cm})$ and two enclosed arms $(30 \mathrm{~cm} \times 5 \mathrm{~cm} \times 10 \mathrm{~cm})$, which were separated by a central platform $(5 \mathrm{~cm} \times 5 \mathrm{~cm})$ with the two identical arms of each type being placed opposite to each other. The height of the maze was $70 \mathrm{~cm}$, and the experiments were conducted under dim red light in a quiet room. Each mouse ( $n=10$ per group) was individually placed onto the central platform of the plus-maze, facing one of the open arms, and was observed/recorded for $5 \mathrm{~min}$ by a trained and blinded-to-treatment observer. The time spent in the open arms and the total distance traveled were used for further analysis. After each session, the maze was cleaned with $70 \%$ ethanol. Data analysis was performed using a computer-operated tracking system (Any-maze, Stoelting, Woods Dale, IL, USA).

\section{Glutamate Uptake Assay}

On the 25th day, the animals ( $n=6$ per group) were sacrificed/dissected and left hippocampal and left frontoparietal cortical brain slices were taken for use in a glutamate uptake assay. The glutamate uptake assay was performed according to Thomazi et al. (2004). Brain hippocampal and frontoparietal cortical slices $(0.4 \mathrm{~mm})$ were obtained using a McIlwain tissue chopper and were pre-incubated for $15 \mathrm{~min}$ at $37^{\circ} \mathrm{C}$ in Hank's balanced salt solution (HBSS), containing $137 \mathrm{mM} \mathrm{NaCl}$, $0.63 \mathrm{mM} \mathrm{Na}_{2} \mathrm{HPO}_{4}, 4.17 \mathrm{mM} \mathrm{NaHCO} 3,5.36 \mathrm{mM} \mathrm{KCl}, 0.44 \mathrm{mM}$ $\mathrm{KH}_{2} \mathrm{PO}_{4}, 1.26 \mathrm{mM} \mathrm{CaCl}, 0.41 \mathrm{mM} \mathrm{MgSO}_{4}, 0.49 \mathrm{mM} \mathrm{MgCl}$, and $1.11 \mathrm{mM}$ glucose, at $\mathrm{pH}$ 7.2. Afterward, 0.66 and $0.33 \mathrm{Ci} \mathrm{ml}^{-1}$ $\mathrm{L}-\left[{ }^{3} \mathrm{H}\right]$ glutamate were added to a final $100 \mathrm{M}$ concentration of glutamate for incubation with hippocampal and cortical samples, respectively. The incubations were stopped after 5 and $7 \mathrm{~min}$ for the hippocampal and cortical samples, respectively, with two ice-cold washes of $1 \mathrm{ml} \mathrm{HBSS}$, which were immediately followed by the addition of $0.5 \mathrm{~N} \mathrm{NaOH}$. The samples were kept in this solution overnight. Nonspecific uptake was measured using the same protocol as described above, with differences in temperature $\left(4^{\circ} \mathrm{C}\right)$ and medium composition $(N$-methyl-D-glucamine instead of sodium chloride). $\mathrm{Na}^{+}$-dependent uptake was considered as the difference between the total uptake and the non-specific uptake. Note that astrocytic transport mediated by GLAST and GLT-1 is responsible for the $\mathrm{Na}^{+}$-dependent glutamate uptake
(Anderson and Swanson, 2000). Both uptakes were performed in triplicate. Any radioactivity that was incorporated into the slices was measured using a liquid scintillation counter.

\section{Western Blotting}

For western blot analysis, right hippocampal and right frontoparietal cortical homogenates $(n=6$, per group) were prepared in PIK buffer (1\% NP-40, $150 \mathrm{mM} \mathrm{NaCl}, 20 \mathrm{mM}$ Tris, $\mathrm{pH} 7.4,10 \%$ glycerol, $1 \mathrm{mM} \mathrm{CaCl}_{2}, 1 \mathrm{mM} \mathrm{MgCl}_{2}, 400 \mu \mathrm{M}$ sodium vanadate, $0.2 \mathrm{mM}$ PMSF, $1 \mu \mathrm{g} / \mathrm{ml}$ leupeptin, $1 \mu \mathrm{g} / \mathrm{ml}$ aprotinin, and $0.1 \%$ phosphatase inhibitor cocktails I and II from Sigma-Aldrich) and centrifuged (Zimmer et al., 2012). Supernatants were collected and total protein was measured using Peterson's method (Peterson, 1977). Samples containing $20 \mu \mathrm{g}$ of protein from the hippocampal homogenate were separated by electrophoresis on a polyacrylamide gel and electrotransferred to PVDF membranes. Protein bands within each sample lane were compared to standard molecular weight markers (Precision Plus Protein ${ }^{\mathrm{TM}}$ Dual Color Standards, Bio-Rad), which were used to identify the molecular weights of proteins of interest. Non-specific binding sites were blocked using Tween-Tris buffered saline (TTBS, $100 \mathrm{mM}$ Tris- $\mathrm{HCl}$, $\mathrm{pH} 7.5$ ) with $5 \%$ albumin for $2 \mathrm{~h}$. Samples were incubated overnight at $4^{\circ} \mathrm{C}$ with primary antibodies against GLT-1 (Abcam, 1:1000), GLAST (Abcam, 1:1000), and $\beta$-actin (Sigma, 1:5000). Following primary antibody incubation, the membranes were incubated with secondary antibodies (anti-rabbit, GE life sciences, 1:3000; anti-mouse, GE life sciences, 1:5000) for $2 \mathrm{~h}$ at room temperature. Films were scanned, and band intensity was analyzed using Image J software (Abramoff et al., 2004).

\section{Statistical Analysis}

Differences between groups were analyzed with analysis of variance (ANOVA) followed by Tukey's post hoc test. Correlations between behavioral assessments and glutamate uptake were analyzed by Pearson's correlation coefficient. The results are presented as mean values \pm SEM. Differences were considered significant at $p<0.05$.

\section{Results}

\section{Long-Term NMDAR Antagonism does not Alter Spontaneous Locomotion but Induces Anxiety-Like Behavior}

Administration of memantine did not cause significant changes in either distance traveled [Figure 1A; $F_{(3,36)}=1.642$, $p=0.1967$ ] or time spent in the central zone [Figure 1B; $\left.F_{(3,36)}=0.1697, p=0.9162\right]$ in the open field. Occupancy plots are used to illustrate the similarities between groups in the open field test (Figure 1C).

\section{Long-Term NMDAR Antagonism Reduced Time Spent in the Light Compartment of the Light-Dark Box}

In the light-dark box (Figure 1G), all of the doses of memantine that were tested significantly reduced the time spent in the light 
compartment by the memantine-administered mice compared to the CO group [Figure 1D; $F_{(3,36)}=7.364$, MN5: $p=0.03$, MN10: $p=0.002$, MN20: $p=0.01]$. However, transition numbers (light to dark) were unrelated to memantine administration [Figure 1E; $\left.F_{(3,36)}=0.8257, p=0.4884\right]$. Additionally, there were no differences among groups in risk assessment index [Figure 1F; $\left.F_{(3,36)}=1.129, p=0.3519\right]$.

\section{Long-Term NMDAR Antagonism Decreased Time Spent in the Open Arms of the Elevated Plus-Maze}

The administration of memantine reduced the time spent by mice in the open arms of the elevated plus-maze (Figure 1J) when compared to the $\mathrm{CO}$ group [Figure $\mathbf{1 H} ; F_{(3,36)}=6.974$, MN5: $p=0.007, \mathrm{MN} 10: p=0.002, \mathrm{MN} 20: p=0.004]$; however, there were no changes in total distance traveled [Figure 1I; $\left.F_{(3,36)}=2.227, p=0.1018\right]$.

\section{Long-Term NMDAR Antagonism Decreased Glutamate Uptake in the Frontoparietal Cortex and Hippocampus without Affecting the Immunocontents of GLAST and GLT-1}

The administration of memantine significantly decreased glutamate uptake in slices of frontoparietal cortex [Figure 2A; $F_{(3,20)}=11.458$, MN5: $p=0.026$, MN10: $p<0.001$, MN20: $p<0.001$ ] and hippocampus [Figure 2D; $F_{(3,20)}=15.008$,
MN5: $p=0.015$, MN10: $p<0.001$, MN20: $p<0.001]$. However, memantine did not alter the immunocontent of GLAST in either the frontoparietal cortex [Figure 2B; $F_{(3,20)}=1.300$, $p=0.3020$ ] or the hippocampus [Figure 2E; $F_{(3,20)}=0.6174$, $p=0.6118]$. Additionally, no alterations were found in the immunocontent of GLT-1 in either the frontoparietal cortex [Figure 2C; $\left.F_{(3,20)}=2.225, p=0.1167\right]$ or the hippocampus [Figure 2F; $\left.F_{(3,20)}=0.1520, p=0.9272\right]$.

\section{Correlation Between Anxiety-Like Behavior and Glutamate Uptake}

A positive correlation was found between time spent in the light compartment of the light dark-box and glutamate uptake in the frontoparietal cortex (Figure 3A; $p<0.0001, R=0.7289$ ) and hippocampus (Figure 3C; $p=0.03, R=0.4337$ ). Time spent in the open arms of the elevated plus-maze test was also correlated with glutamate uptake in the frontoparietal cortex (Figure 3B; $p=0.03, R=0.4313$ ) and hippocampus (Figure 3D; $p=0.01$, $R=0.4815)$.

\section{Discussion}

Our results demonstrated that long-term antagonism of NMDAR by memantine induces anxiety-like behavior in healthy CF1 mice. Additionally, memantine decreased glutamate uptake activity in the frontoparietal cortex and in the hippocampus

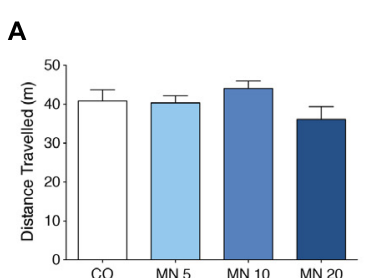

B

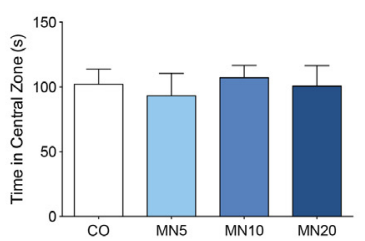

c
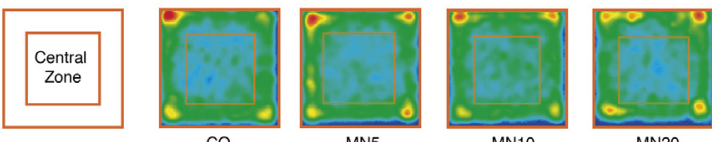

H

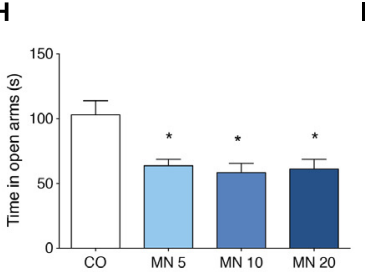

I

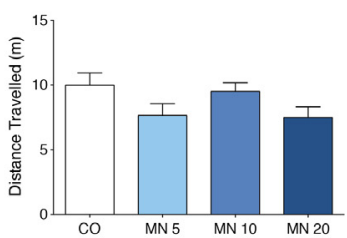

FIGURE 1 | Long-term NMDAR antagonism does not alter spontaneous locomotor and exploratory behavior, but induces anxiety-like behavior. (A) Total distance traveled in the open field. (B) Time in central zone in the open field. (C) Open field apparatus and occupancy plots. (D) Time in light compartment in the light-dark box. (E) Number of transitions in the light-dark box. (F) Risk assessment

$\mathbf{J}$
D

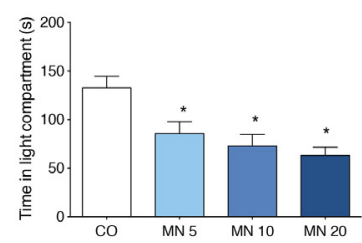

$\mathbf{F}$

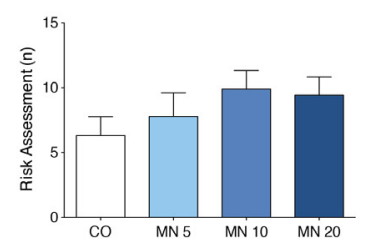

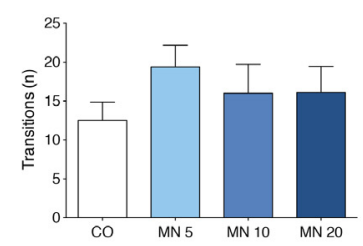

G

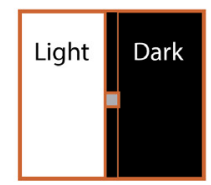

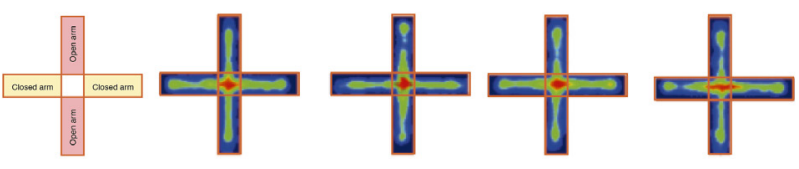

index in the light-dark box. (G) Light-dark box apparatus. (H) Time in open arms in the elevated plus-maze. (I) Distance traveled in the elevated plus-maze. (J) Elevated plus-maze apparatus and occupancy plots. Groups: control (CO), memantine $5 \mathrm{mg}$ (MN 5), memantine $10 \mathrm{mg}$ ( $M N$ 10), and memantine $20 \mathrm{mg}(\mathrm{MN} 20) ; n=10$ per group. Data are presented as mean values \pm SEM. 
D

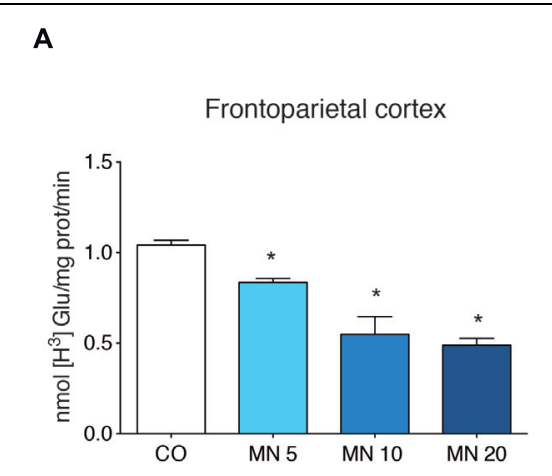

B

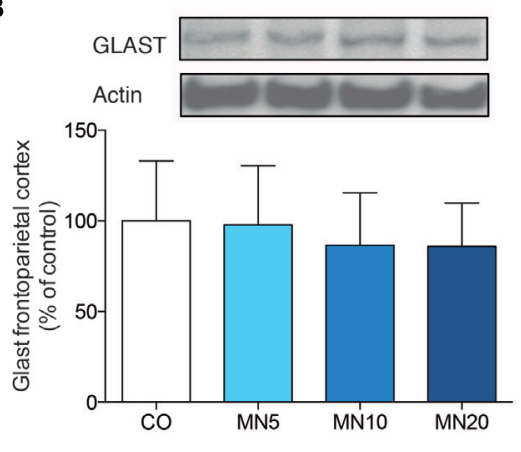

E

Hippocampus

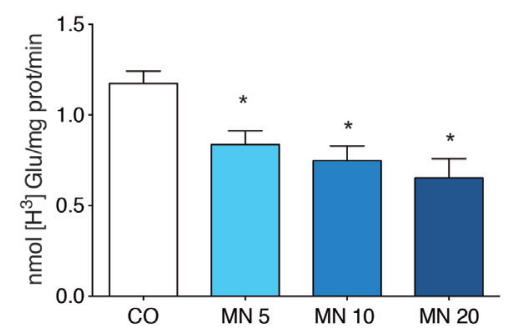

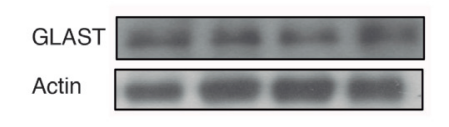

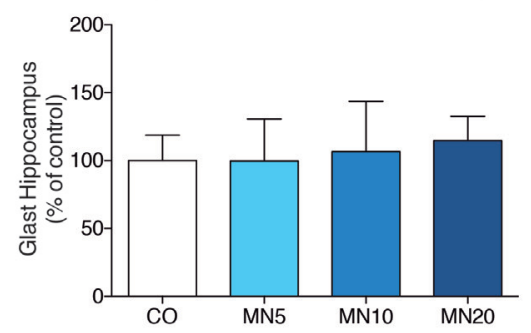

C

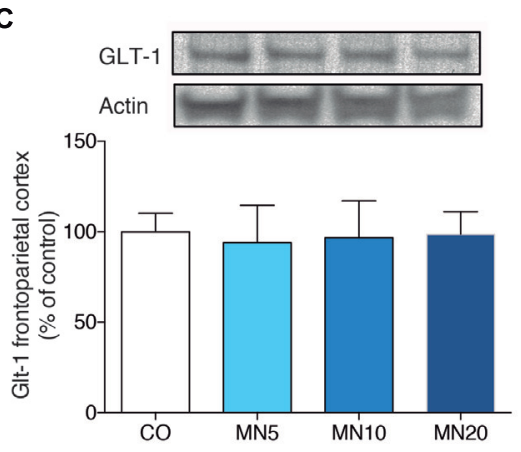

F

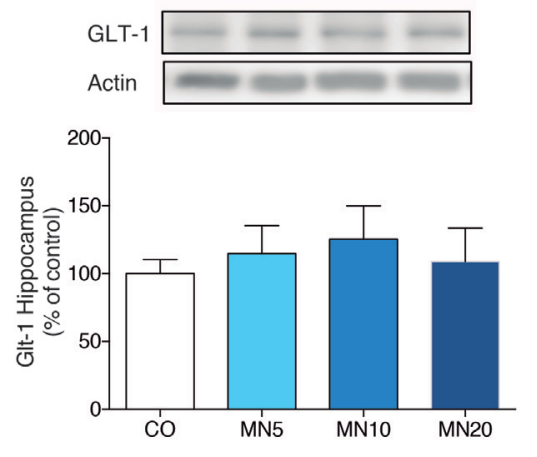

FIGURE 2 | Long-term NMDAR antagonism decreases glutamate uptake in the frontoparietal cortex and hippocampus, but does not alter astroglial transporter immunocontent. (A) Glutamate uptake in slices of frontoparietal cortex. (B) Immunocontent of GLAST in the frontoparietal cortex. (C) Immunocontent of GLT-1 in the frontoparietal cortex. (D) Glutamate uptake in slices of hippocampus. (E) Immunocontent of GLAST in the frontoparietal cortex. (F) Immunocontent of GLT-1T in the frontoparietal cortex. Groups: CO, memantine $5 \mathrm{mg}$ (MN 5), memantine $10 \mathrm{mg}$ (MN 10), and memantine $20 \mathrm{mg}$ (MN 20); $n=6$ per group. Data are presented as mean values \pm SEM. $* p<0.05$ among groups. with this phenomenon correlating with anxiety-like behavior. By contrast, the immunocontents of the astroglial glutamate transporters GLT-1 and GLAST were not affected.

Long-term administration of memantine did not induce significant changes in the spontaneous locomotion and exploratory activity of mice in the open field test. These findings imply that neither the dose nor the regimen of memantine that was used in our work led to non-specific effects such as sedation, which can potentially impair performance in anxiety-like tasks. This finding is in agreement with previous reports that have demonstrated that memantine administration does not alter locomotion or exploratory profiles (Reus et al., 2010). Conversely, we also showed that long-term memantine administration at doses of 5,10 , or $20 \mathrm{mg} / \mathrm{kg}$ leads to an anxiogenic phenotype that is manifested by decreased time spent in the light compartment (light-dark box) and reduced time spent in open arms (elevated plus-maze). Interestingly, a previous work showed that the administration of MK801, another non-competitive NMDAR antagonist, to rats induced an anxiety-like phenotype in the elevated plus-maze (Solati, 2011). In contrast to MK801, high doses of memantine $(100 \mathrm{mg} / \mathrm{kg})$ increased time spent in open arms, implying an anxiolytic effect. However, doses ranging from 10 to $30 \mathrm{mg} / \mathrm{kg}$ decreased time spent in open arms ( 40\%), without reaching statistical significance, which suggests a trend representative of an anxiogenic-like effect (Minkeviciene et al., 2008). Additionally, chronic antagonism of NMDAR with piperine18 exacerbated anxiogenic symptoms in C57BL/6 mice (Hanson et al., 2014). Indeed, it would appear that the antagonism of NMDAR does not follow a linear dose-response effect in terms of modulating anxiety-like behavior.

It has also been shown that memantine plays a role in controlling synaptic glutamate release. In fact, $\mathrm{Lu}$ et al. (2010) have shown that memantine suppresses glutamate release in cortical synaptosomes. In this study, however, we showed that long-term administration of memantine reduces glutamate uptake without affecting the glutamate transporters expression, GLT-1 and GLAST, in the frontoparietal cortex and hippocampus. Based on these findings, one could argue that memantine-induced reduction of glutamate uptake by astrocytes is a direct adaptive response to the reduced release of glutamate by neurons. This assumption reinforces a theoretical framework in which neurons and astrocytes are capable of sensing each other while regulating tripartite glutamatergic synapses (Wade et al., 2013; Karus et al., 2015). However, further studies using additional methodologies, such as immunostaining and electron microscopy, are necessary to better understand neuron-astrocyte coupling in the context of anxiety-like phenotypes.

Interestingly, a recent work demonstrated that blockade of GLT-1 in the central amygdala was also capable of inducing anxiety-like behavior, which reinforces the association between 
A

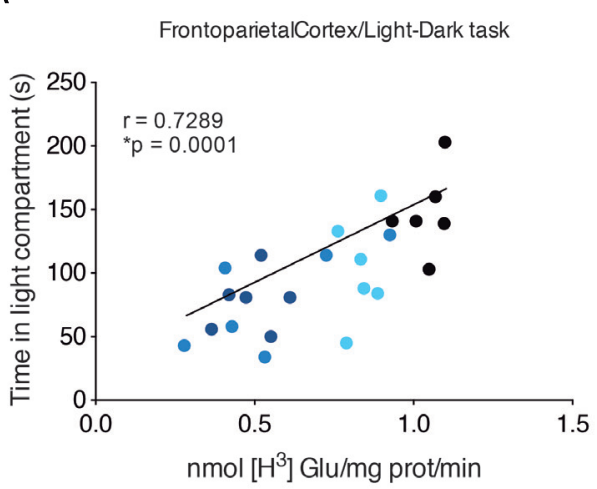

C

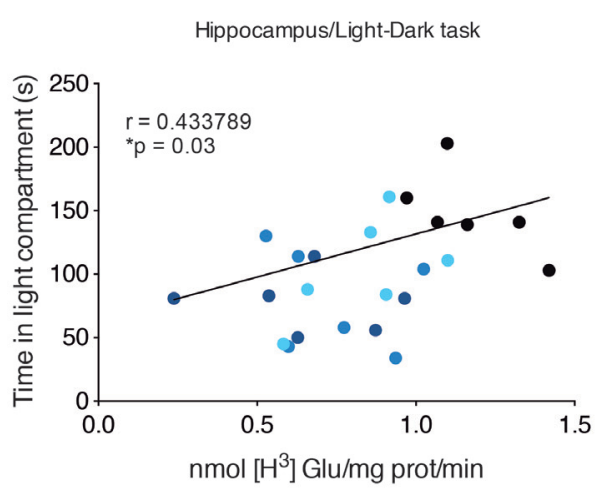

FIGURE 3 | Anxiety-like behavior correlates with glutamate uptake. (A) Linear correlation between time spent in light compartment during the light/dark task and glutamate uptake in slices of frontoparietal cortex. (B) Linear correlation between time spent in open arms and glutamate uptake in slices of frontoparietal cortex. (C) Linear correlation between time spent in light compartment during light/dark task and
B

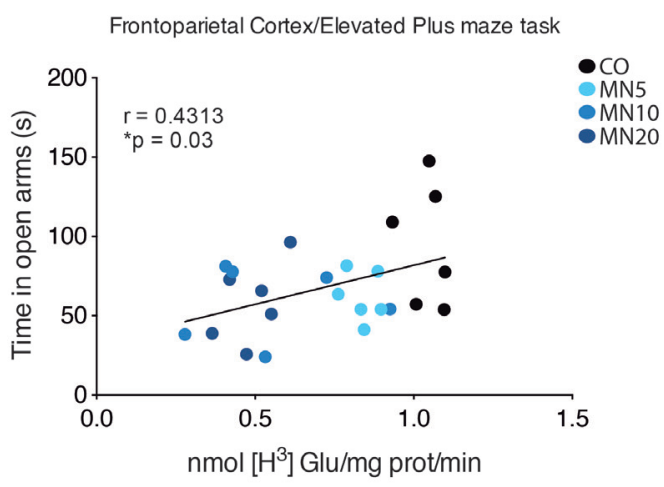

D

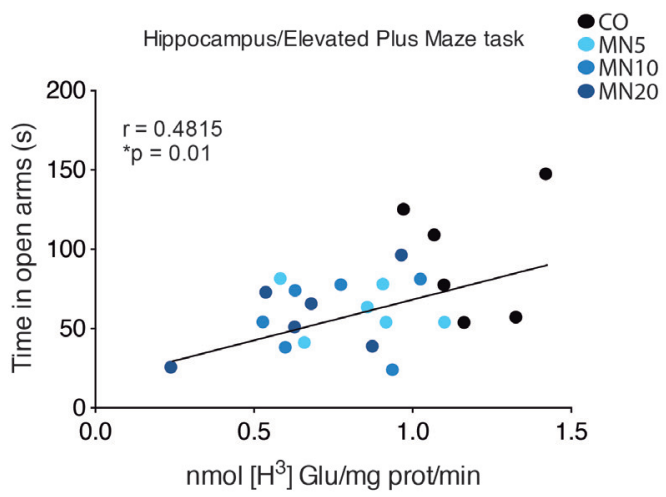

glutamate uptake in slices of hippocampus. (D) Linear correlation between time spent in open arms in elevated plus-maze test and glutamate uptake in slices of hippocampus. Groups: CO, memantine $5 \mathrm{mg}$ (MN 5), memantine $10 \mathrm{mg}$ (MN 10), and memantine $20 \mathrm{mg}$ (MN 20); $n=24$. Data presented by one animal per point. $* p<0.05$. astrocytic glutamate uptake activity and the development of an anxiety phenotype (John et al., 2015). Remarkably, we were able to show through linear correlation that decreased glutamate uptake activity in the hippocampus and frontoparietal cortex was significantly correlated with an increased anxiety-like response.

\section{Conclusion}

Long-term NMDAR antagonism by memantine induces an anxiety phenotype that is associated with reduced glutamate uptake activity in healthy CF-1 mice, which suggests that interactions between neurons and astrocytes can shape anxietyrelated behavior.

\section{Author Contributions}

EZ was responsible for the design, acquisition, analysis, interpretation, drafting, and approval of the final version of the manuscript. VT, EK, MA, KZ, RA, and GH were responsible for acquisition, analysis, interpretation, and approval of the final version of the manuscript. AM, DS, and RV were responsible for interpretation, drafting, critical revision, and approval of the final version of the manuscript. LV was responsible for the design, interpretation, drafting, critical revision, and approval of the final version of the manuscript.

\section{Acknowledgments}

This work was supported by the following Brazilian agencies and grants: National Counsel of Technological and Scientific Development (CNPq), CAPES, FAPERGS, Brazilian Institute of Neuroscience (IBNnet), FINEP, and National Institute of Science and Technology (INCT) - Excitotoxicity and Neuroprotection.

\section{Supplementary Material}

The Supplementary Material for this article can be found online at: http://journal.frontiersin.org/article/10.3389/fncel.2015. 00219/abstract 


\section{References}

Abramoff, M. D., Magalhaes, P. J., and Ram, S. J. (2004). Processing with ImageJ. Biophotonics Intern. 11, 36-42.

Anderson, C. M., and Swanson, R. A. (2000). Astrocyte glutamate transport: review of properties, regulation, and physiological functions. Glia 32, 1-14. doi: 10.1002/1098-1136(200010)32:1<1::AID-GLIA10>3.0.CO;2-W

Bechtholt-Gompf, A. J., Walther, H. V., Adams, M. A., Carlezon, W. A. Jr., Ongur, D., and Cohen, B. M. (2010). Blockade of astrocytic glutamate uptake in rats induces signs of anhedonia and impaired spatial memory. Neuropsychopharmacology 35, 2049-2059. doi: 10.1038/npp. 2010.74

Clement, Y., and Chapouthier, G. (1998). Biological bases of anxiety. Neurosci. Biobehav. Rev. 22, 623-633. doi: 10.1016/S0149-7634(97)00058-4

Cortese, B. M., and Phan, K. L. (2005). The role of glutamate in anxiety and related disorders. CNS Spectr. 10, 820-830.

Crawley, J., and Goodwin, F. K. (1980). Preliminary report of a simple animal behavior model for the anxiolytic effects of benzodiazepines. Pharmacol. Biochem. Behav. 13, 167-170. doi: 10.1016/0091-3057(80)90067-2

Danbolt, N. C. (2001). Glutamate uptake. Prog. Neurobiol. 65, 1-105. doi: 10.1016/S0301-0082(00)00067-8

Danbolt, N. C., Storm-Mathisen, J., and Kanner, B. I. (1992). An $[\mathrm{Na}++$ $\mathrm{K}+$ ]coupled L-glutamate transporter purified from rat brain is located in glial cell processes. Neuroscience 51, 295-310. doi: 10.1016/0306-4522(92) 90316-T

Gross, C., and Hen, R. (2004). The developmental origins of anxiety. Nat. Rev. Neurosci. 5, 545-552. doi: 10.1038/nrn1429

Hanson, J. E., Meilandt, W. J., Gogineni, A., Reynen, P., Herrington, J., Weimer, R. M., et al. (2014). Chronic GluN2B antagonism disrupts behavior in wildtype mice without protecting against synapse loss or memory impairment in Alzheimer's disease mouse models. J. Neurosci. 34, 8277-8288. doi: 10.1523/JNEUROSCI.5106-13.2014

John, C. S., Sypek, E. I., Carlezon, W. A., Cohen, B. M., Ongur, D., and Bechtholt, A. J. (2015). Blockade of the GLT-1 transporter in the central nucleus of the amygdala induces both anxiety and depressivelike symptoms. Neuropsychopharmacology 40, 1700-1708. doi: 10.1038/npp. 2015.16

Karus, C., Mondragao, M. A., Ziemens, D., and Rose, C. R. (2015). Astrocytes restrict discharge duration and neuronal sodium loads during recurrent network activity. Glia 63, 936-957. doi: 10.1002/glia.22793

Leasure, J. L., and Decker, L. (2009). Social isolation prevents exercise-induced proliferation of hippocampal progenitor cells in female rats. Hippocampus 19, 907-912. doi: 10.1002/hipo.20563

Lee, Y., Son, H., Kim, G., Kim, S., Lee, D. H., Roh, G. S., et al. (2013) Glutamine deficiency in the prefrontal cortex increases depressive-like behaviours in male mice. J. Psychiatry Neurosci. 38, 183-191. doi: 10.1503/jpn. 120024

Lehre, K. P., and Danbolt, N. C. (1998). The number of glutamate transporter subtype molecules at glutamatergic synapses: chemical and stereological quantification in young adult rat brain. J. Neurosci. 18, 8751-8757.

Lu, C. W., Lin, T. Y., and Wang, S. J. (2010). Memantine depresses glutamate release through inhibition of voltage-dependent $\mathrm{Ca}^{+}{ }^{+}$entry and protein kinase $\mathrm{C}$ in rat cerebral cortex nerve terminals: an NMDA receptor-independent mechanism. Neurochem. Int. 57, 168-176. doi: 10.1016/j.neuint.2010. 05.010

Machado-Vieira, R., Ibrahim, L., Henter, I. D., and Zarate, C. A. Jr. (2012). Novel glutamatergic agents for major depressive disorder and bipolar disorder. Pharmacol. Biochem. Behav. 100, 678-687. doi: 10.1016/j.pbb.2011. 09.010

Machado-Vieira, R., Manji, H. K., and Zarate, C. A. (2009). The role of the tripartite glutamatergic synapse in the pathophysiology and therapeutics of mood disorders. Neuroscientist 15, 525-539. doi: 10.1177/10738584093 36093

Minkeviciene, R., Banerjee, P., and Tanila, H. (2008). Cognition-enhancing and anxiolytic effects of memantine. Neuropharmacology 54, 1079-1085. doi: 10.1016/j.neuropharm.2008.02.014

Muller, A. P., Zimmer, E. R., Kalinine, E., Haas, C. B., Oses, J. P., Martimbianco De Assis, A., et al. (2012). Physical exercise exacerbates memory deficits induced by intracerebroventricular STZ but improves insulin regulation of $\mathrm{H} 2 \mathrm{O} 2$ production in mice synaptosomes. J. Alzheimers Dis. 30, 889-898. doi: 10.3233/JAD-2012-112066

Nemeroff, C. B. (2003). The role of GABA in the pathophysiology and treatment of anxiety disorders. Psychopharmacol. Bull. 37, 133-146.

Nutt, D. J., and Malizia, A. L. (2001). New insights into the role of the GABA(A)benzodiazepine receptor in psychiatric disorder. Br. J. Psychiatry 179, 390-396. doi: 10.1192/bjp.179.5.390

Pellow, S. (1986). Anxiolytic and anxiogenic drug effects in a novel test of anxiety: are exploratory models of anxiety in rodents valid? Methods Find Exp. Clin. Pharmacol. 8, 557-565.

Peterson, G. L. (1977). A simplification of the protein assay method of Lowry et al. which is more generally applicable. Anal. Biochem. 83, 346-356. doi: 10.1016/0003-2697(77)90043-4

Pilc, A., Wierońska, J. M., and Skolnick, P. (2013). Glutamate-based antidepressants: preclinical psychopharmacology. Biol. Psychiatry 73, 1125-1132. doi: 10.1016/j.biopsych.2013.01.021

Reus, G. Z., Stringari, R. B., Kirsch, T. R., Fries, G. R., Kapczinski, F., Roesler, R. et al. (2010). Neurochemical and behavioural effects of acute and chronic memantine administration in rats: further support for NMDA as a new pharmacological target for the treatment of depression? Brain Res. Bull. 81, 585-589. doi: 10.1016/j.brainresbull.2009.11.013

Riaza Bermudo-Soriano, C., Perez-Rodriguez, M. M., Vaquero-Lorenzo, C., and Baca-Garcia, E. (2012). New perspectives in glutamate and anxiety. Pharmacol. Biochem. Behav. 100, 752-774. doi: 10.1016/j.pbb.2011. 04.010

Sani, G., Serra, G., Kotzalidis, G. D., Romano, S., Tamorri, S. M., Manfredi, G., et al. (2012). The role of memantine in the treatment of psychiatric disorders other than the dementias: a review of current preclinical and clinical evidence. CNS Drugs 26, 663-690. doi: 10.2165/11634390-000000000-00000

Schroeter, M. L., Abdul-Khaliq, H., Sacher, J., Steiner, J., Blasig, I. E., and Mueller, K. (2010). Mood disorders are glial disorders: evidence from in vivo studies. Cardiovasc. Psychiatry Neurol. 2010:780645. doi: 10.1155/2010/ 780645

Schwartz, T. L., Siddiqui, U. A., and Raza, S. (2012). Memantine as an augmentation therapy for anxiety disorders. Case Rep. Psychiatry 2012:749796. doi: 10.1155/2012/749796

Silvestre, J. S., Nadal, R., Pallares, M., and Ferre, N. (1997). Acute effects of ketamine in the holeboard, the elevated-plus maze, and the social interaction test in Wistar rats. Depress. Anxiety 5, 29-33. doi: 10.1002/(SICI)15206394(1997)5:1<29::AID-DA5>3.0.CO;2-0

Solati, J. (2011). Dorsal hippocampal N-methyl-d-aspartate glutamatergic and delta-opioidergic systems modulate anxiety behaviors in rats in a noninteractive manner. Kaohsiung J. Med. Sci. 27, 485-493. doi: 10.1016/j.kjms.2011. 06.011

Szabo, S. T., Machado-Vieira, R., Yuan, P., Wang, Y., Wei, Y., Falke, C., et al. (2009) Glutamate receptors as targets of protein kinase $\mathrm{C}$ in the pathophysiology and treatment of animal models of mania. Neuropharmacology 56, 47-55. doi: 10.1016/j.neuropharm.2008.08.015

Tariot, P. N., Farlow, M. R., Grossberg, G. T., Graham, S. M., Mcdonald, S., and Gergel, I. (2004). Memantine treatment in patients with moderate to severe Alzheimer disease already receiving donepezil: a randomized controlled trial. JAMA 291, 317-324. doi: 10.1001/jama.291.3.317

Thomazi, A. P., Godinho, G. F., Rodrigues, J. M., Schwalm, F. D., Frizzo, M. E., Moriguchi, E., et al. (2004). Ontogenetic profile of glutamate uptake in brain structures slices from rats: sensitivity to guanosine. Mech. Ageing Dev. 125, 475-481. doi: 10.1016/j.mad.2004. 04.005

Wade, J., Mcdaid, L., Harkin, J., Crunelli, V., and Kelso, S. (2013) Biophysically based computational models of astrocyte $\sim$ neuron coupling and their functional significance. Front. Comput. Neurosci. 7:44. doi: 10.3389/fncom.2013.00044

Zarate, C. Jr., Machado-Vieira, R., Henter, I., Ibrahim, L., Diazgranados, N., and Salvadore, G. (2010). Glutamatergic modulators: the future of treating mood disorders? Harv. Rev. Psychiatry 18, 293-303. doi: 10.3109/10673229.2010.511059

Zhou, Y., and Danbolt, N. C. (2014). Glutamate as a neurotransmitter in the healthy brain. J. Neural. Transm. 121, 799-817. doi: 10.1007/s00702-014-1180-8 
Zimmer, E. R., Kalinine, E., Haas, C. B., Torrez, V. R., Souza, D. O., Muller, A. P., et al. (2012). Pretreatment with memantine prevents Alzheimer-like alterations induced by intrahippocampal okadaic acid administration in rats. Curr. Alzheimer Res. 9, 1182-1190. doi: 10.2174/156720512804142877

Conflict of Interest Statement: The authors declare that the research was conducted in the absence of any commercial or financial relationships that could be construed as a potential conflict of interest.
Copyright (๑) 2015 Zimmer, Torrez, Kalinine, Augustin, Zenki, Almeida, Hansel, Muller, Souza, Machado-Vieira and Portela. This is an open-access article distributed under the terms of the Creative Commons Attribution License (CC BY). The use, distribution or reproduction in other forums is permitted, provided the original author(s) or licensor are credited and that the original publication in this journal is cited, in accordance with accepted academic practice. No use, distribution or reproduction is permitted which does not comply with these terms. 